\title{
Recession stresses mental health system
}

$\mathrm{T}$ The recession has not devastated the health care sector like it has other industries, such as manufacturing and automotives, but it has still made an impact. When a large number of people lose their jobs in a short period, there tends to be an increase in demand for medical services in some areas, such as mental health. In other areas, however, demand tends to decrease. Some dentists, for example, fear that many people who lose their employer-sponsored dental benefits will forgo preventive care, which could result in small problems blossoming into big ones.

Stress-related ailments, in particular, become more common during tough financial times. More than $40 \%$ of working adults in Canada are worried they will lose their jobs, and 1 in 3 are having trouble sleeping; experiencing overall anxiety; or suffering from muscle aches, headaches and physical tension, according to the Desjardins Financial Security National Health Survey. More than half of the participants in the survey, released May 4, blame the recession for upsetting their work-life balance.

These findings prompted the Canadian Mental Health Association to issue a press release, in which it called for "all employers, in both the public and private sectors, to broaden access to and funding for mental health programs in the workplace."

The current stress on mental health systems in the United States, where the recession struck earlier and was accompanied by a devastating mortgage crisis, might be a preview of what's in store for Canadian mental health workers. US mental health professionals report growing traffic at emergency rooms, mental health clinics, therapists' offices and on mental health hotlines. Some doctors report seeing more cases of alcohol abuse, drug overdoses, panic disorders, depression and stress-related physical problems, such as abdominal and chest pains.

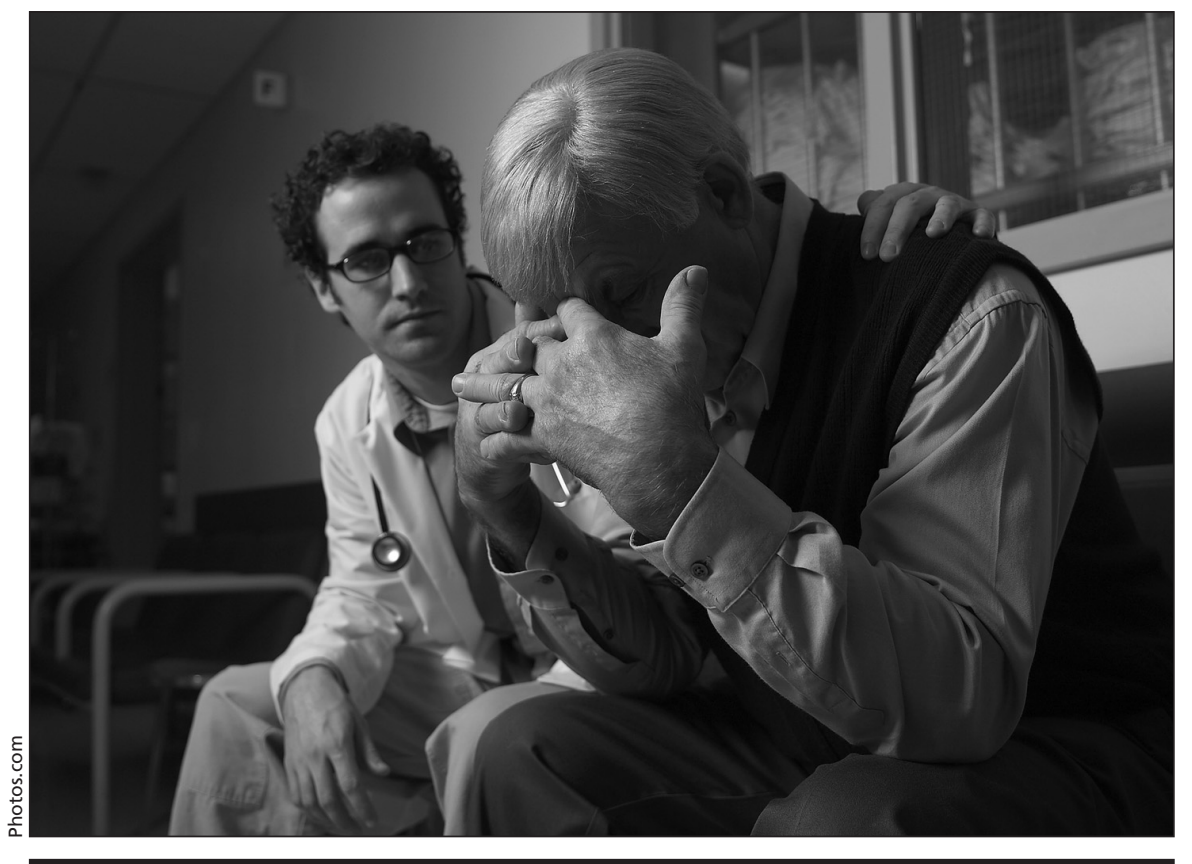

As the recession deepens, some doctors report that they are seeing more patients with stress-related physical problems and depression.

The largest US health insurer, UnitedHealth Group Inc., reported that hospital admissions for psychiatric services rose $10 \%$ from 2007 to 2008 . Calls to the hotline of the Mental Health Association of Nassau County in Hempstead, New York, increased 20\% from September 2008 to April 2009. At Nassau University Medical Center in East Meadow, New York, the number of cases needing psychiatric consult is up $75 \%$ from 2007.

In Canada, primary care providers will likely be the first to notice a jump in mental health problems -- such as depression and substance abuse - that could result from widespread unemployment and underemployment. The College of Family Physicians of Canada asked family doctors, in an April newsletter, how the recession was affecting their practices. Nearly $40 \%$ of those who responded said they now treat many patients for stress-related problems caused by economic worry and another $49 \%$ responded that they see such problems occasionally. One doctor wrote that job losses "are increasing intensity of pre-existing problems in their lives resulting in relationship breakdowns, anxiety, depressions and uncontrolled anger."

It is not only people who have lost their jobs that are under mental stress, say Dr. Stan Yaren, a psychiatrist in Winnipeg, Manitoba. Recessions can be equally stressful for those still in the workplace. "People still at work are still vulnerable. Their options and choices are narrowing. People may be staying in jobs that they otherwise would move out of. And the fear of the loss of a job is often as bad as an actual job loss."

For those who have lost their jobs, the ensuing financial hardships can affect family life and, subsequently, mental health. But problems can arise even for the unemployed with no immediate money worries. "The dynamics of not being at work are perhaps not as easily recognized. It affects interpersonal relationships in families. People are together more without struc- 
ture, and there could be more personal conflicts arising in marriages and other family situations," says Yaren. "Probably, at this stage, psychiatrists and specialists are not seeing the brunt of what is yet to come."

Unlike mental health professionals, dentists are likely to see a decrease in patient traffic. A major reason people visit dentists less often during a recession is not just loss of income but loss of dental coverage. A recent study indicated that people with dental insurance visit a dentist more than twice as often as those without insurance ( $J$ Can Dent Assoc 2007;73[1]:57). In an article published in May, the association's manager of health policy and information, Costa Papadopoulous, wrote: "As unemployment rates rise and Canadians lose health insurance coverage, a direct potential consequence is reduced visits to the dentist." (J Can Dent Assoc 2009;75[4]:267-8).

Some of the dental procedures people put off, such as teeth whitening, are merely cosmetic. Of more concern to dentists is when patients cancel checkups or forgo preventive care. This might save patients money in the short term, dentists say, but could cost them more in the end, if minor problems are allowed to grow into larger -- and more costly -- problems.

"I can certainly tell you that the CDA [Canadian Dental Association] is concerned about the economic downturn, about the loss of jobs and loss of dental benefits," says Don Friedlander, president of the Canadian Dental Association. "Our focus is prevention, prevention, prevention. ... Prevention is the key to reducing long-term costs."

Some cash-strapped people also neglect eye care during recessions. For instance, a recent poll of contact lens wearers in Britain found that almost $25 \%$ would consider switching to a cheaper brand, $20 \%$ were likely to wear disposable contact lenses for longer than recommended by optometrists and $10 \%$ would consider having fewer checkups. The General Optical Coun- cil, which regulates the optometry profession in Britain, issued a public statement in May warning people that highrisk contact lens practices — others include wearing torn lenses instead of replacing them and cleaning lenses less frequently to save on solution costs could lead to significant eye problems.

"I think what's happened over the last 6 to 8 months is that we have proven that the idea of optometry being recession proof is a myth," says Derek MacDonald, an optometrist in Waterloo, Ontario. "We haven't suffered as much as our colleagues in retail or industry. We are less discretionary than buying a new car or furniture, but there is an element of discretion involved."

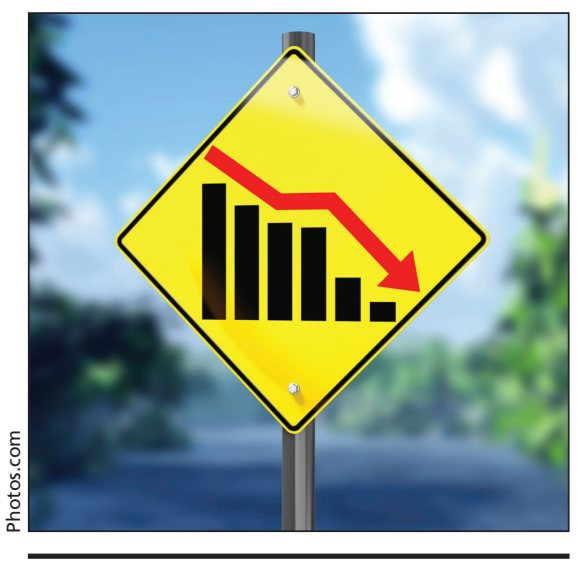

The decline in economic indicators is expected to result in more mental health problems.

It would be unwise to put off basic preventive eye care, says MacDonald, because undetected smaller problems tend to grow into larger problems that not only cost people more money but could compromise their vision. "When a patient comes in after having put off something for 2 or 4 years and we find something ... then you are behind the 8-ball."

Of any area in health care, perhaps cosmetic surgery would be expected to suffer the most during a recession. Indeed, Canadian plastic surgery associations have been warning members for some time to expect a big drop in busi- ness, according to Dr. Bryan Callaghan, a plastic surgeon in Ottawa, Ontario. "We were preparing for a significant adjustment in our practice. ... We have not seen the expected downturn for cosmetic surgery here that one would expect. That could be because we have a more stable socio-economic base here, with the government as a major employer."

American plastic surgeons appear to have been affected much more than their Canadian colleagues, and Dr. Achilles Thoma, a plastic surgeon in Hamilton, Ontario, has a theory as to why. "There are fewer Canadian plastic surgeons that are devoted only to cosmetic surgery here. There is a buffer in reconstructive surgery," he says. "Some cosmetic practices have gone bankrupt in the United States."

Just as plastic surgeons in Canada appear to be buoying the economic downturn, health care workers who provide primary care and rely on government funding are also likely to fare well, says Steve Morgan, association director of the Centre for Health Services and Policy Research at the University of British Columbia in Vancouver, British Columbia. Governments tend to avoid cutting health care funding during economic downturns because of increased demand for services for stress-related problems. "A downturn in the economy means there is going to be an increase in medical needs," says Morgan, a health care economist. "The stress and anxiety of economic change will cause people to not be well, both mentally and physically."

Though governments may not cut funding during recessions, they are not likely to invest in expansions to health care infrastructure or fund new services, says Morgan. "When the economy is in the tank the government doesn't have much money to throw around for these new services, which aren't as sexy as new buildings or a new bridge or highway." — Roger Collier, CMAJ

DOI:10.1503/cmaj.091123 